\title{
The Effect Of Short, Intermediate And Long Duration Of Swimming On Pulmonary Function Tests.
}

\author{
${ }^{1}$ Nilesh Netaji Kate, ${ }^{2}$ Chandrika G. Teli, ${ }^{3}$ Ambareesha Kondam, ${ }^{4}$ Madhuri A, \\ ${ }^{5}$ Suresh M, ${ }^{6}$ Chandrashekar M. \\ ${ }^{I}$ M.D. Physiology. Assistant Professor, Dept. of Physiology, Meenakshi Medical College \& R.I, Kancheepuram \\ 631552, Tamilnadu, INDIA. \\ ${ }^{2}$ M.S. Anatomy. Assistant Professor. Meenakshi Medical College and research institute, Kanchipuram-631552, \\ Tamilnadu, India. \\ ${ }^{3,4,5}$ Msc Physiology. Tutor, Dept. of Physiology, Meenakshi Medical College \& R.I, Kancheepuram 631552, \\ Tamilnadu, INDIA. \\ ${ }^{6}$ M.D Physiology. Professor and Head, Dept. of Physiology, Meenakshi Medical College \& R.I, \\ Kancheepuram 631552, Tamilnadu, INDIA.
}

\begin{abstract}
Background \& Objectives: As muscular strength can be increased by regular exercise, it was decided to study the effect of strenuous swimming on the pulmonary function tests, as it involves both, the total body muscular activity and excessive use of chest and abdominal muscles following periods of breath holding, which is a part of training for competitive swimmers.

Methods: Selected lung volumes and capacities were determined on 60 swimmers of three different groups i.e. group I- swimming experience of less than 2 years, Group II- between 2 to 5 years, and Group III- >5 years and compared with 60 controls. The purpose of the study is to find the effect of swimming for different duration on pulmonary function tests i.e. forced vital capacity $(F V C)$, forced expiratory volume $\left(F E V_{I}\right)$, inspiratory Capacity (IC) And tidal Volume (TV)

Result: Forced vital capacity (FVC), Forced expiratory volume ( $\left.F E V_{1}\right)$, Inspiratory Capacity (IC) And Tidal Volume (TV) of controls with swimmers of group II and III there is statistically significant and statistically highly significant increase in values were observed respectively.

Conclusion: The swimming exercise for intermediate and long duration of time i.e. more than two (2) years produces a significant improvement in the pulmonary functions. This improvement is directly proportional to the increased duration of swimming.
\end{abstract}

Key words: Exercise, Pulmonary function test, Swimmers,

\section{Introduction}

Performance in athletics is influenced by many factors such as aerobics and anaerobic capacity, muscle power, neuromuscular co-ordination technique, motivation etc. The aerobic capacity is the dominant factor in endurance events like long distance running, walking and games ${ }^{1}$. The thoracic and abdominal muscle strength plays an important role in most of pulmonary function. As muscular strength can be increased by regular exercise, it is decided to study the effect of strenuous swimming on the pulmonary function tests, as it involves both, the total body muscular activity and excessive use of chest and abdominal muscles following periods of breath holding, which is a part of training for competitive swimmers. ${ }^{2}$

The purpose of choosing swimmers instead of any other sports persons was that previous studies have shown that swimming produces maximum effect on the lungs compared to any other sport. ${ }^{3}$ Regular swimming practice should produce a positive effect on the lungs by increasing pulmonary capacity and thereby improving the lung functioning.

\section{Material And Methods}

The present study was conducted in the department of physiology, Government medical college Aurangabad. With the approval of ethical committee the sample size selected were one hundred and twenty (120) subjects between the age group of twenty (20) to forty five (45) years. The procedures followed were in accordance with the ethical standards of the responsible committee on human experimentation (institutional) and with the Helsinki Declaration of 1975 that was revised in 2000. (http://www.wma.net/e/policy/17-c_e.html.) The swimmers were divided into three groups depending upon the duration of their swimming experience Group I: - Duration of swimming less than two (2) years, Group II:- Duration of swimming between two (2) to five (5) years, Group III:- Duration of swimming more than five (5) years. Swimming exercise in the form of free style swimming for 2 hrs/day for 5 days a week was practiced. 
The non-swimmers selected for study were people from Government Medical College Aurangabad in similar age group. They were not practicing any athletic event. Pulmonary function tests were recorded using MEDGRAPHICS U.S.A. BODY PLETHYSMOGRAPH, ELITE DX MODEL NO-830001-005. After volume calibration at three (3) liters and temperature calibration at room temperature to give values at BTPS.

The parameters taken into account in this study were forced vital capacity (FVC), forced expiratory volume in one second $\left(\mathrm{FEV}_{1}\right)$, inspiratory capacity (IC) and tidal volume (TV),. Written consent was taken and the subject was asked to breathe as per the instructions to record the parameters. To avoid the diurnal variation test procedure were performed in the morning from 9 a.m. to 12 noon. To eliminate the effect of age, height, weight and sex on the different parameters percentage predicted values were considered for statistical analysis.

\section{Statistical Analysis.}

All the information is statistically analyzed using SPSS software (17.0 version). Obtained data was analyzed using one way analysis of variance (ANOVA).P $<0.005$ had taken as statistically significant.

\section{Results:}

The present study shows that swimmers have higher values of lung function as compared with nonswimmers. It is also observed that this improvement in the lung function is not significant $(\mathrm{P}>0.1)$ in swimmers of group I, but significant $(\mathrm{P}<0.05)$, in swimmers of group II and highly significant $(\mathrm{P}<0.0001)$, in swimmers of group III.

\section{Discussion}

In the present study, it is observed that there is significant increase in vital capacity in swimmers of group II and group III, these findings can be explained on the basis of better endurance of respiratory muscles. Another factor which may contribute to explain our result may be greater lung size in swimmers of group III as compared to swimmers of group I. Training of muscles of the shoulder girdle leads to an increase in the vital capacity by the increase strength of accessory muscles of expiration. ${ }^{4}$

The initial part of an expiratory forced vital capacity (FVC) curve depends on non-bronchopulmonary factors like neuromuscular factors and mechanical equipment factors e.g. inertial distortion. The terminal portion of the curve is relatively variable due to factors like maintenance and co-ordination of efforts, which are exercise dependent to some extent. The middle portion is relatively free. The first $20 \%$ of the FVC is affected by non-bronchopulmonary factors. ${ }^{\mathbf{5}}$ there are observations from longitudinal studies that well trained individuals retained the same vital capacity at the age of forty to forty-five years as twenty years earlier. ${ }^{6,7}$

Ventilatory capacity may sometimes be increased by endurance training of the respiratory muscles. One of factors affecting the forced expiratory volume is airway resistance. Thus, increased respiratory muscles endurance rather than decreased airway resistance appears to be the probable explanation for increased FEV1 in swimmers of group I and swimmers of group III as compared to controls in the present study. ${ }^{4}$ Improvement in the PFT values could be due to hypertrophy of the diaphragm which requires hard work for prolonged periods of time. ${ }^{\mathbf{8}}$ Adolescents habituated to high level of physical activity had on an average greater lung volume than their sedentary counterparts of comparable age and body size which was attributed to reduced resistance to expiration in respiratory muscles. ${ }^{9}$ Earlier studies have been reported that increased values of FVC, FEV1, and PEFR in sportsmen playing football, hockey, basketball, volleyball, and in swimmers as compared to controls. Thus confirming that the exercise has a facilitative effect on lungs. ${ }^{10,11,12,13,14 .}$

As Inspiratory capacity is the only parameter which improve higher than other parameters in swimmers of group I. Therefore it is presumed that Inspiratory capacity may be the first parameter to improve with swimming probably due to improved strength of the accessory muscles of respiration. Accessory muscles of respiration do not contract during quite breathing and are inactive but are exercised during severe muscular exercise. ${ }^{15}$ Earlier studies revealed that, swimmers have larger inspiratory capacities than either the runners or the controls. ${ }^{16}$

Large lungs leads to increased tidal volume contributing more to the ventilatory minute volume than in the subjects with smaller lungs. Size of the lung is one of the factors that determine the tidal volume. Athletic training is known to increase the lung size. ${ }^{5}$

In the present study increased tidal volume in both swimmers of group II and in swimmers of group III can be attributed to the increased lung size. ${ }^{5}$

\section{Conclusion}

The present study concludes that exercise in the form of swimming for more than two (2) years produces a significant improvement in the pulmonary functions. This improvement is directly proportional to the increased duration of swimming. So swimming can be recommended so as to improve the lung function of an individual. 


\section{References}

[1] Malhotra M. S. et al. Functional capacity and body composition of different classes of Indian athletes. Indian J. Physiol. and Pharmacol. 1972; 16(4): 301-308.

[2] Pherwni A.V, Desai A. G, and Solepure A. B: A study of pulmonary function of competitive swimmers. Indian. J. Physiol. pharmac. 1989, vol. 33. (4); 228-232.

[3] Lakhera S. C. et al: Pulmonary function of Indian athletes and sportsmen: comparison with American athletes. Indian. J. Physiol. Pharmacol. 1984; 28(3): 187-194.

[4] Cotes J E: Introduction. In: Lung Function Assessment and Application in Medicine, $1^{\text {st }}$ edition. Blackwell Scientific Publications, oxford, 1965; 1-13.

[5] Comroe J. J. Physiology of respiration $.2^{\text {nd }}$ Ed. Year Book Medical Publishers Incorporated, Chicago, U. S. A. 1975; $94-141$.

[6] Astrand P. O. et al. Reduction in maximal oxygen uptake with age. Journal of Applied Physiology, $1973 ; 35: 649$.

[7] Astrand P. O. and Rodahl K, Text book of work Physiology: $3^{\text {rd }}$ edition, New York, Mc. GrawHill publication, 1986.

[8] Balfour N, Szonim and Hamilton M. H. Lung volumes and its subdivisions. Respiratory Physiology. C. V. Mosby and company ed III, 1976; 40-46.

[9] Lakhera S. C. et al, Lung function in middle distance adolescent runners. Indian Journal of Physiology and Pharmacology. 1994, 38(2): 117-120.

[10] Andrew G. M, Becklake M. R, Guleria J. S and Bates D. V: Heart and lung functions in swimmers and non-athletes during growth. J. Applied Physiol. 1972; 32: 245-251.

[11] Holmer ET. Al. Haemodynamics and respiratory responses compared in swimming and running. Journal of Applied physiology. 1974; 37(1), 49-54.

[12] Mehrotra P. K. et al: Pulmonary functions in Indian sportsmen playing different sports. Indian J. Physiol Pharmacol. 1998; 42 (3): 412-416.

[13] Curstian et al. Journal of sports medicine physical fitness. 1985, 21(2): 179-185.

[14] Newmann F. et al. Effect of exercise, body and lung size on co-diffusion in athletes and non-athletes. Journal of Applied Physiology. 1962; 17: 649-655.

[15] Campbell E J N. The respiratory muscles and the mechanics of breathing. Year Book Medical Publishers Incorporated-1958 as quoted by Comroe J. H.

[16] Cordain L, Tucker A, Moon D and Stager J. M: Lung volumes and maximal respiratory pressure in collegiate swimmers and runners. Res Q Exerc Sport.1990; Mar; 61(1): 70-74.

Table 1: Comparison of Mean percentage predicted values of different parameters in controls, Group I, Group II

\begin{tabular}{|c|c|c|c|c|}
\hline & $\begin{array}{c}\text { CONTROLS } \\
\text { Mean } \pm \text { SD } \\
(\mathrm{N}=60)\end{array}$ & $\begin{array}{c}\text { GR I } \\
\text { Mean } \pm \text { SD } \\
(\mathrm{N}=16)\end{array}$ & $\begin{array}{c}\text { GR II } \\
\text { Mean } \pm \text { SD } \\
(\mathrm{N}=20)\end{array}$ & $\begin{array}{c}\text { GR III } \\
\text { Mean } \pm \text { SD } \\
(\mathrm{N}=24)\end{array}$ \\
\hline FVC & $\begin{array}{c}69.41 \\
\pm 9.87\end{array}$ & $\begin{array}{c}70.25 \\
\pm 8.43 * \mathbf{N S} \\
\end{array}$ & $\begin{array}{c}80.3 \\
\pm 2.27 * * * \mathbf{H S} \\
\end{array}$ & $\begin{array}{c}100.2 \\
\pm 7.69 * * * \mathbf{H S}\end{array}$ \\
\hline $\operatorname{FEV}_{1}$ & $\begin{array}{r}71.86 \\
\pm 7.42 \\
\end{array}$ & $\begin{array}{c}72.25 \\
\pm 4.34 * \mathbf{N S} \\
\end{array}$ & $\begin{array}{c}81.9 \\
\pm 6.68 * * \mathrm{~S} \\
\end{array}$ & $\begin{array}{c}99.16 \\
\pm 9.2 * * * \mathbf{H S} \\
\end{array}$ \\
\hline IC & $\begin{array}{r}82.35 \\
\pm 10.87 \\
\end{array}$ & $\begin{array}{c}85.68 \\
\pm 9.87 * \mathrm{NS} \\
\end{array}$ & $\begin{array}{c}88.5 \\
\pm 10.82 * * \mathbf{S} \\
\end{array}$ & $\begin{array}{c}94.66 \\
\pm 13.18 * * * \mathbf{H S} \\
\end{array}$ \\
\hline TV & $\begin{array}{c}1.49 \\
\pm 0.60\end{array}$ & $\begin{array}{c}1.54 \\
\pm 0.67 * \mathbf{N S}\end{array}$ & $\begin{array}{c}1.60 \\
\pm 0.35 * * * \mathbf{H S}\end{array}$ & $\begin{array}{c}1.71 \\
\pm 0.31 * * * \mathbf{H S}\end{array}$ \\
\hline
\end{tabular}

* p > 0.1, **p $<0.05, * * * p<0.0001$, NS-----NOT SIGNIFICANT,

S--SIGNIFICANT, HS_HIGHLY SIGNIFICANT, SD: Standard deviation. 